\title{
Microbiological Quality, Physicochemical Properties, and Antioxidant Capacity of Honey Samples Commercialized in the Moroccan Errachidia Region
}

\author{
Nawal El Menyiy, Mourad Akdad, Youssef Elamine $\mathbb{D}$, and Badiaa Lyoussi $\mathbb{1}$ \\ Laboratory of Physiology, Pharmacology \& Environmental Health, Faculty of Science, University Sidi Mohamed Ben Abdellah, \\ Fez, Morocco \\ Correspondence should be addressed to Badiaa Lyoussi; lyoussi@gmail.com
}

Received 23 December 2019; Revised 21 March 2020; Accepted 23 March 2020; Published 2 June 2020

Academic Editor: Luca Campone

Copyright (c) 2020 Nawal El Menyiy et al. This is an open access article distributed under the Creative Commons Attribution License, which permits unrestricted use, distribution, and reproduction in any medium, provided the original work is properly cited.

\begin{abstract}
An examination of possible effect of hot desert climate on microbiological safety and physicochemical and antioxidant properties of honey marketed in the province of Errachidia in Morocco was made. The assessment of microbiological properties showed no alarming sign of microbiological contamination or quality deterioration. This can be seen by the low moisture content in all analysed samples, which was below $20 \%$ (the maximum allowed in honey), and acid pH which was raging from $3.32 \pm 0.05$ to $4.37 \pm 0.12$. The ash content values ranged between $0.02 \pm 0.01 \%$ and $0.23 \pm 0.001 \%$, and the electrical conductivity ranged between $87.4 \pm 0.42$ and $1148.06 \pm 2.16 \mathrm{mS} / \mathrm{cm}$. Considering the mineral content, the potassium was the most abundant species in all the analysed samples. The phenol content values varied from $17.35 \pm 2.15 \mathrm{mg} \mathrm{GAE} / 100 \mathrm{~g}$ in H7 to 219.026 $2.26 \mathrm{mg} \mathrm{GAE} / 100 \mathrm{~g}$ in H9. Similarly, the same behavior was seen in the case of the other bioactive subfamilies of phenolic compound flavonoid content. Hence, the highest value of flavonoids, flavones, and flavanols was detected in $\mathrm{H} 9$, and the minimum value was observed in sample H7. A negative correlation was found between the bioactive fraction of honey samples and free radical scavenging activity assessed as $\mathrm{IC}_{50}$, the concentration of honey that scavenges $50 \%$ of the used free radicals. The bioactive fraction, the antioxidant assays, and their correlation values showed the same profile in comparison to the honey samples of other Moroccan regions.
\end{abstract}

\section{Introduction}

Honey is a natural sweet substance made by Apis mellifera bees from the nectar, from the secretion of different parts of the flowering plants, or from some insect excretions which honeybees collect, transform, and store until maturation [1]. Depending on the botanical origin, honey chemical composition varies greatly. Honey major fraction is constituted by carbohydrates (mainly glucose and fructose), followed by water [2].In addition, honey contains small amounts (minor fractions) of other components such as proteins, free amino acids, organics acids, polyphenols, vitamins, minerals, enzymes, and other phytochemicals [3].

The abovementioned compounds are responsible for attributing some characterizing physicochemical properties, such as $\mathrm{pH}$, acidity, electrical conductivity, and amongst others. For each parameter, the international community has established several standards, which, when exceeded, may indicate the unsuitability for the human consumption, or at least reduces its quality and so its market value [4].

In Morocco, beekeeping is an important economic activity. About 35,000 beekeepers are managing 375,000 hives and producing 2,500-3,500 tons of honey per year. This production may reach 16,000 tons by 2020 , according to estimations of the Department of Agriculture [5]. The physicochemical and microbiological studies of Moroccan honeys become an important task to respond to consumer's demands and insure the quality of the increasing production. Many studies have been published for this reason $[2,6,7]$. 
Honey may be influenced by different factors that reduce its quality. Honey samples could be considered as unsafe for consumption when it is highly contaminated by infectious bacterial or mould strains [8]. The quality gets deteriorated also by bad storage conditions and/or heat processing. It is reported also that experiencing hot weather may accelerate the deterioration rate. Authors stated that 10 days at $32^{\circ} \mathrm{C}$ may cause the same deterioration honey quality as it does 100 to 120 days at $21^{\circ} \mathrm{C}$ [9]. It must be mentioned those effects may be increased by low hygienic care during beekeeping practices [7].

Errachidia Region in Morocco is characterized by a hot desert climate with a mean annual precipitation of about $85 \mathrm{~mm}$ and maximum temperature reaching up to $50^{\circ} \mathrm{C}$ during the hottest months [10]. Such climate, if associated with low quality practices, may be accompanied by producing low quality honey. Hence, the aim of the present contribution was to evaluate the physicochemical characteristics ( $\mathrm{pH}$, colour, moisture, ash content, and electrical conductivity) and the microbial properties (total mesophilic aerobic flora (TMAF), Salmonella, Shigella, sulfite-reducing Clostridium, coliforms and fecal coliforms, moulds, and yeasts) of samples commercialized in Errachidia. Furthermore, the purchased samples were analysed for their mineral contents ( $\mathrm{K}, \mathrm{Na}, \mathrm{Ca}, \mathrm{Mg}$, and $\mathrm{Fe}$ ) and antioxidant activity.

\section{Material and Methods}

2.1. Honey Samples. A total of fourteen commercial honey samples were obtained from beekeeping active associations of Errachidia City (Morocco). Until the analyses, honey samples were kept at $20-22^{\circ} \mathrm{C}$ in their commercial flasks. Table 1 shows the codes of the samples, the production years, the collection sites, and their botanic source as declared in the label.

\subsection{Microbiological Characterization of Honey Samples.} The total mesophilic aerobic flora (TMAF), Salmonella, Shigella, sulfite-reducing Clostridium, coliforms and fecal coliforms, moulds, and yeasts were evaluated for each sample. $90 \mathrm{ml}$ of peptone water solvent was used for the homogenization of $10 \mathrm{~g}$ of honey, and serial decimal dilutions were made using the same solution of peptone. The total mesophilic aerobic flora (TMAF) was assessed employing the plate count agar following the indications of the standard NP-3788:2002 [11]. For Salmonella and Shigella detections, two protocols were followed, namely, those of ISO 6579:2002 [12] and ISO 21567:2004 [13], respectively. The microbial assessment was also extended to the determination of sulphite-reducing Clostridium, coliforms, and fecal coliforms that were analysed using SPS agar media [14] and the most probable number technique [15], respectively. While mould and yeast counts were evaluated following the protocol of ISO 21527-2 : 2008 [16]. Each test was performed in triplicate, and the microbial counts were expressed as colony-forming units per gram of honey (cfu/g).
TABLE 1: Latin name, places of collection, and year of production of honey samples.

\begin{tabular}{lccc}
\hline Honey & Latin name & Location & Year of harvest \\
\hline H1 & Citrus sinensis & Sidi Kacem & 2016 \\
H2 & Thymus vulgaris & Errachidia & 2016 \\
H3 & Ceratonia siliqua & Khenifra & 2016 \\
H4 & Eruca sativa & Tafrouat & 2016 \\
H5 & Ceratonia siliqua & Boudnib & 2016 \\
H6 & Ziziphus lotus & Errachidia & 2016 \\
H7 & Peganum harmala & Midelt & 2016 \\
H8 & Euphorbia resinifera & Beni Mellal & 2016 \\
H9 & Acacia tortilis & Alnif & 2016 \\
H10 & Tamarix aucheriana & Errachidia & 2016 \\
H11 & Rosmarinus officinalis & Midelt & 2016 \\
H12 & Foeniculum vulgare Mill & Errachidia & 2016 \\
H13 & Origanum vulgare & Rich & 2016 \\
H14 & Euphorbia echinus & Agadir & 2016 \\
\hline
\end{tabular}

2.3. pH, Moisture, Electrical Conductivity, and Ash Content. The harmonized methods of the International Honey Commission were followed for the determination of physicochemical parameters, namely, $\mathrm{pH}$, ash content, electrical conductivity, and moisture [4]. The results of each parameter are the means of three replicates.

2.4. Colour and Melanoidin Content Estimations. Colour intensity and melanoidin content were estimated by absorbance measurements. Light absorbance of honey solutions $(50 \% \mathrm{w} / \mathrm{v})$ at $635 \mathrm{~nm}$ is used employing the algorithm: mmPfund $=-38.7+371.39 \times$ absorbance [17]. The browning index (estimating the melanoidin content) is obtained by measuring the net absorbance of the same honey solutions at $450 \mathrm{~nm}$ and $720 \mathrm{~nm}$ [18].

2.5. Determination of Mineral Elements. The mineral content of honey samples was determined following the method described by [19]. First, the ash content was obtained by calcination of $5 \mathrm{~g}$ of honey at $550^{\circ} \mathrm{C}$ for 5 hours. $5 \mathrm{ml}$ of $0.1 \mathrm{M}$ nitric acid was added to the ashes and heated to complete dryness. Then, $10 \mathrm{ml}$ of $0.1 \mathrm{M}$ nitric acid was added, and the volume was made up to $25 \mathrm{ml}$ with distilled water. Inductively coupled plasma mass spectrometry (ICP-MS) was used, and the values were calculated as $\mathrm{mg}$ of each mineral element per $\mathrm{kg}$ of honey.

2.6. Total Phenol Content. The total polyphenol content was estimated in honey solutions employing the Folin-Ciocalteu reduction method. A series of gallic acid dilutions as described previously was used to establish the calibration curve [20]. Briefly, a mixture was made by mixing $100 \mu \mathrm{L}$ of honey solution $(10 \% \mathrm{w} / \mathrm{v}), 0.5 \mathrm{ml}$ of Folin-Ciocalteu $(0.2 \mathrm{~N})$ reagent, and $400 \mu \mathrm{L}$ of $7.5 \% \mathrm{Na}_{2} \mathrm{CO}_{3}$. After $2 \mathrm{~h}$ incubation, the absorbance was measured at $765 \mathrm{~nm}$. The resulting values were expressed as mg gallic acid equivalent/100 g (mg GAE/ $100 \mathrm{~g})$. 
2.7. Total Flavonoid Content. The ability of flavonoids to react with the aluminum chloride is the core reaction for the estimation of their content. The method described by [21] was used for total flavonoid quantification. The quercetin was used as a standard, and the values (means of three replicates) were calculated as $\mathrm{mg} \mathrm{QE} / 100 \mathrm{~g}$ honey.

2.8. Flavone and Flavonol Content. Flavone and flavonol estimations were carried out as described previously [22]. The results were expressed also as $\mathrm{mg} \mathrm{QE} / 100 \mathrm{~g}$ (quercetin equivalent).

2.9. Estimation of Total Antioxidant Capacity by Phosphomolybdate Assay. The ability of honey samples to reduce the ammonium molybdate was used to estimate their total antioxidant capacity [23]. Briefly, $1 \mathrm{ml}$ of the reagent solution made by mixture of $0.6 \mathrm{M}$ sulfuric acid, $28 \mathrm{mM}$ sodium phosphate, and $4 \mathrm{mM}$ ammonium molybdate was added to $100 \mu \mathrm{L}$ of honey solution. The reaction tubes were vortexed and then boiled $\left(95^{\circ} \mathrm{C}\right.$ for $\left.90 \mathrm{~min}\right)$ in water bath. After cooling at room temperature, the absorbance at $695 \mathrm{~nm}$ was measured and the results were calculated against a calibration curve of ascorbic acid.

2.10. Determination of Free Radical Scavenging Activity by DPPH Method. The determination of DPPH radical scavenging activity of honey samples was monitored following the previously described procedure [24]. Briefly, $825 \mu \mathrm{L}$ of DPPH solution $(0.1 \mathrm{mM})$ was mixed with $150 \mu \mathrm{L}$ of honey solutions (different dilutions). After one hour of incubation in the dark at room temperature, the absorbance of the mixture was measured at $517 \mathrm{~nm}$ temperature. This absorbance was then used to calculate the $\mathrm{IC}_{50}$, the concentration of honey required for the inhibition of $50 \%$ of DPPH free radicals.

2.11. Reducing Power Assay (Iron Reducing Activity). To test the ability of honey samples to reduce iron ions, $150 \mu \mathrm{L}$ of honey solution (different dilutions were used) was mixed with $200 \mu \mathrm{L}$ of $0.2 \mathrm{M}$ potassium buffer ( $\mathrm{pH} 6.6$ ) and $200 \mu \mathrm{L}$ of ferricyanide $(1 \% \mathrm{w} / \mathrm{v})$. A water bath $\left(50^{\circ} \mathrm{C}\right)$ was used for the incubation of the reactional medium for $20 \mathrm{~min}$. At last $200 \mu \mathrm{L}$ of trichloroacetic acid $(10 \% \mathrm{w} / \mathrm{v}), 600 \mu \mathrm{L}$ of distilled water, and $120 \mu \mathrm{L}$ of ferric chloride $(0.1 \% \mathrm{w} / \mathrm{v})$ were added to the reaction [25]. The resulting absorbance at $700 \mathrm{~nm}$ was used and compared to an ascorbic acid reference standard.

2.12. Statistical Analysis. One-way ANOVA followed by the post hoc Tukey multiple comparison test using Graph Pad Prism 5 software was used for mean comparisons. Correlations between different physicochemical parameters were achieved by Pearson's correlation coefficient $(r)$ at a significance level of 99\% $(p<0.01)$. The integration of all analysed parameters was made possible using the principal component analysis (PCA). MultBiplot64 running in MATLAB R2018a was used.

\section{Results and Discussion}

3.1. Microbiological Evaluation. Microbial counts in the analysed samples are summarized in Table 2. Total mesophilic aerobic flora was detected in six honey samples with the highest level in sample $\mathrm{H} 8(370 \mathrm{cfu} / \mathrm{g})$ and the lowest level in samples $\mathrm{H} 4$ and $\mathrm{H} 7(10 \mathrm{cfu} / \mathrm{g})$. Those results still conform to the French standard (ECOC0300092V, 2003), which determines $1000 \mathrm{cfu} / \mathrm{g}$ as the maximum allowed. The presence of mesophilic aerobic flora in honey indicates nonhygienic practices during the production and storage processes. The absence of coliforms and fecal coliforms in all analysed samples is an indication of the sanitary quality of the analysed honey samples [26].Another indicator of unsafety of honey for human consumption is the presence of sulfate-reducing anaerobes, namely, Salmonella and Shigella. Our results indicated the absence of these microorganisms in all honey samples (Table 2). Furthermore, no mold and yeast contamination was detected in samples of the present study. In previous studies, authors reported honey contamination and linked it to the deterioration of some physicochemical features $[27,28]$.

3.2. Quality Control Analysis. The physicochemical characteristics (colour, melanoidins, $\mathrm{pH}$, moisture, electrical conductivity, and ash) of the studied honey samples are shown in Table 3. In general, honey is naturally acidic, which is resulting from the presence of many organic acids. The importance of this parameter relies on its influences on honey texture, stability, and shelf life, [29]. The acidic feature was clearly seen in the analysed sample with $\mathrm{pH}$ values varying between $3.32 \pm 0.05$ in $\mathrm{H} 9$ and $4.37 \pm 0.12$ in $\mathrm{H} 8$. Similar values were reported for other Moroccan honey samples $[6,30]$ as well as for Algerian, Portuguese, Brazilian, and Turkish honeys $[21,31]$. The water content of honey, a determinant parameter considering the development of undesirable microorganisms, is known to be influenced by seasonal differences, environmental conditions, and honey maturity in honeycombs [32].The observed values ranged between $15.4 \%$ in sample H13 and $19.6 \%$ in sample H14 (Table 3). The moisture content for all analysed samples was below the established limit by the European Community, 2004, and Codex Standard for Honey, 2001.

The ash content is an indicator of the botanical origin (floral, mixed, or honeydew) and its the mineral content [31]. This parameter in the investigated samples ranged from $0.02 \pm 0.01 \%$ (H11) to $0.23 \pm 0.001 \%$ (H9), being below $0.6 \%$, the determined threshold for honey samples [1].Electrical conductivity of honey is certainly one of the most crucial parameters for determining the physical characteristics of this natural product and can also be essential for the characterization of unifloral honeys [33]. The obtained results varied between $87.4 \pm 0.42$ in sample $\mathrm{H} 1$ and a maximum of $1148.06 \pm 2.16$ in sample H9 (Table 3 ).

Honey colour estimation is usually linked to the presence of phenols, flavonoids, and mineral and pollen content and may be influenced by storage conditions and processing [31] . In the present work, variability was seen in colour intensity, 
TABLe 2: Microbial profiles (in cfu/g) of the honey samples.

\begin{tabular}{|c|c|c|c|c|c|c|}
\hline Honey & TMAF & Sulfate-reducing anaerobic & Coliforms and fecal coliforms & Salmonella & Shigella & Moulds and yeasts \\
\hline $\mathrm{H} 1$ & 20 & Abs & Abs & Abs & Abs & Abs \\
\hline $\mathrm{H} 2$ & Abs & Abs & Abs & Abs & Abs & Abs \\
\hline $\mathrm{H} 3$ & 30 & Abs & Abs & Abs & Abs & Abs \\
\hline $\mathrm{H} 4$ & 10 & Abs & Abs & Abs & Abs & Abs \\
\hline H5 & Abs & Abs & Abs & Abs & Abs & Abs \\
\hline H6 & Abs & Abs & Abs & Abs & Abs & Abs \\
\hline $\mathrm{H7}$ & 10 & Abs & Abs & Abs & Abs & Abs \\
\hline $\mathrm{H} 8$ & 370 & Abs & Abs & Abs & Abs & Abs \\
\hline H9 & Abs & Abs & Abs & Abs & Abs & Abs \\
\hline H10 & Abs & Abs & Abs & Abs & Abs & Abs \\
\hline H11 & Abs & Abs & Abs & Abs & Abs & Abs \\
\hline H12 & Abs & Abs & Abs & Abs & Abs & Abs \\
\hline $\mathrm{H} 13$ & Abs & Abs & Abs & Abs & Abs & Abs \\
\hline H14 & 60 & Abs & Abs & Abs & Abs & Abs \\
\hline Min & 0 & n.a & n.a & n.a & n.a & n.a \\
\hline Max & 370 & n.a & n.a & n.a & n.a & n.a \\
\hline Mean & 35.72 & n.a & n.a & n.a & n.a & n.a \\
\hline SD & 97.72 & n.a & n.a & n.a & n.a & n.a \\
\hline
\end{tabular}

n.a, non applicable; Abs, absence.

determined at A635: white colour in samples H4, H5, H7, and H11 samples and amber in H2, H8, and H14 (Table 3). The colour intensity strongly correlated with melanoidins' content $(r=0.911 ; p<0.01)$ (Table 4$)$. This correlation was also indicted previously in other Moroccan honey samples $[6,30]$.

3.3. Mineral Content. The mineral content is one of the biomarkers used for geographical origin determination of the presence of heavy metals indicate the presence of environmental contamination sources [34]. In this work, chemical analysis of major minerals present in Moroccan honey was performed (Table 3 ). According to the obtained results, potassium was the most abundant species in all analysed samples, with values ranging between $87.4 \pm 0.42 \mathrm{mg} / \mathrm{kg}$ in sample $\mathrm{H} 1$ and $1148.06 \pm 2.16 \mathrm{mg} / \mathrm{kg}$ in sample H9. The calcium content was the second most abundant and varied between $55.05 \pm 0.53 \mathrm{mg} / \mathrm{kg}$ and $232.6 \pm 0.28 \mathrm{mg} / \mathrm{kg}$, followed by sodium content ranging between $25.98 \pm 1.42 \mathrm{mg} / \mathrm{kg}$ and $164.01 \pm 2.83 \mathrm{mg} / \mathrm{kg}$. It has to be mentioned that similar values in honey were reported previously $[30,34]$.

\subsection{Biochemical Analysis}

3.4.1. Phenolic and Flavonoid Compounds in Honeys. The quantification of polyphenols and flavonoids is shown in Table 5, and the correlations between these bioactive compounds and other assessed parameters are illustrated in Table 4 . The minimum total phenolic content value was seen in sample H7 (17.35 $\pm 2.15 \mathrm{mg} \mathrm{GAE} / 100 \mathrm{~g})$, while sample H9 presented the highest amount amongst the analysed honey samples with a value of $219.026 \pm 2.26 \mathrm{mg}$ GAE/ $100 \mathrm{~g}$. The same observation was made for flavonoid content from one side and flavone and flavanol contents from another side. The highest values of both groups of compounds was detected in $\mathrm{H} 9$ with values of $36.30 \pm 0.37 \mathrm{mg} \mathrm{QE} / 100 \mathrm{~g}$ and $18.23 \pm 2.82 \mathrm{mg} \mathrm{QE} / 100 \mathrm{~g}$, respectively, while the minimum value was observed in sample $H 7$ with values of $0.71 \pm 0.9 \mathrm{mg}$ $\mathrm{QE} / 100 \mathrm{~g}$ and $0.3 \pm 0.84 \mathrm{mg} \mathrm{QE} / 100 \mathrm{~g}$. Two highlights could be made from these results: first, the influence of the floral origin in determining the content of bioactive compounds in honey, being so in accordance with previous works [35]. Second, the suggestion of significant correlation between the evaluated contents. Such correlations have been confirmed in other studies $[21,31]$. It has to be mentioned that the amounts of polyphenols and flavonoids found in the studied honey samples were in the range of those of different monofloral honeys from Brazil (61.16-111.37 mg GAE/ $100 \mathrm{~g})[36]$.

3.4.2. Antioxidant Activity. In this work, the antioxidant activity of the honey samples was measured using three different methods (reducing power, DPPH, and total antioxidant activity). As expected, samples with high bioactive compound contents possessed the highest antioxidant activity. The total antioxidant activity expressed as $\mathrm{mg}$ of ascorbic acid equivalent/g of honey (AAE) exceeded in sample H9 with a value of $223.86 \pm 2.04 \mathrm{mg}$ AAE/ $100 \mathrm{~g}$ and had the minimum value in sample $\mathrm{H} 7(20.57 \pm 0.01 \mathrm{mg}$ AAE/ $100 \mathrm{~g}$ ). Sample H9 presented also the best ability to scavenge the DPPH free radicals and to reduce the ferulic ions in the reducing power assay, with values of $\mathrm{IC}_{50}=4.79 \pm 0.05 \mathrm{mg} /$ $\mathrm{mL}$ and $\mathrm{IC}_{50}=1.87 \pm 0.18 \mathrm{mg} / \mathrm{mL}$, respectively (Table 5).

For correlation analysis, a significant negative correlation was found between the $\mathrm{IC}_{50}$ of $\mathrm{DPPH}$ scavenging activity from one side and phenols $(r=-0.790 ; p<0.01)$ and flavonoids $(r=-0.659 ; p<0.01)$ from the other side (Table 4).Such correlation is similar to that reported in previous works $[6,31]$, indicating that the antioxidant activity of honey is due to the presence of mentioned bioactive compounds. This may be confirmed the observed 


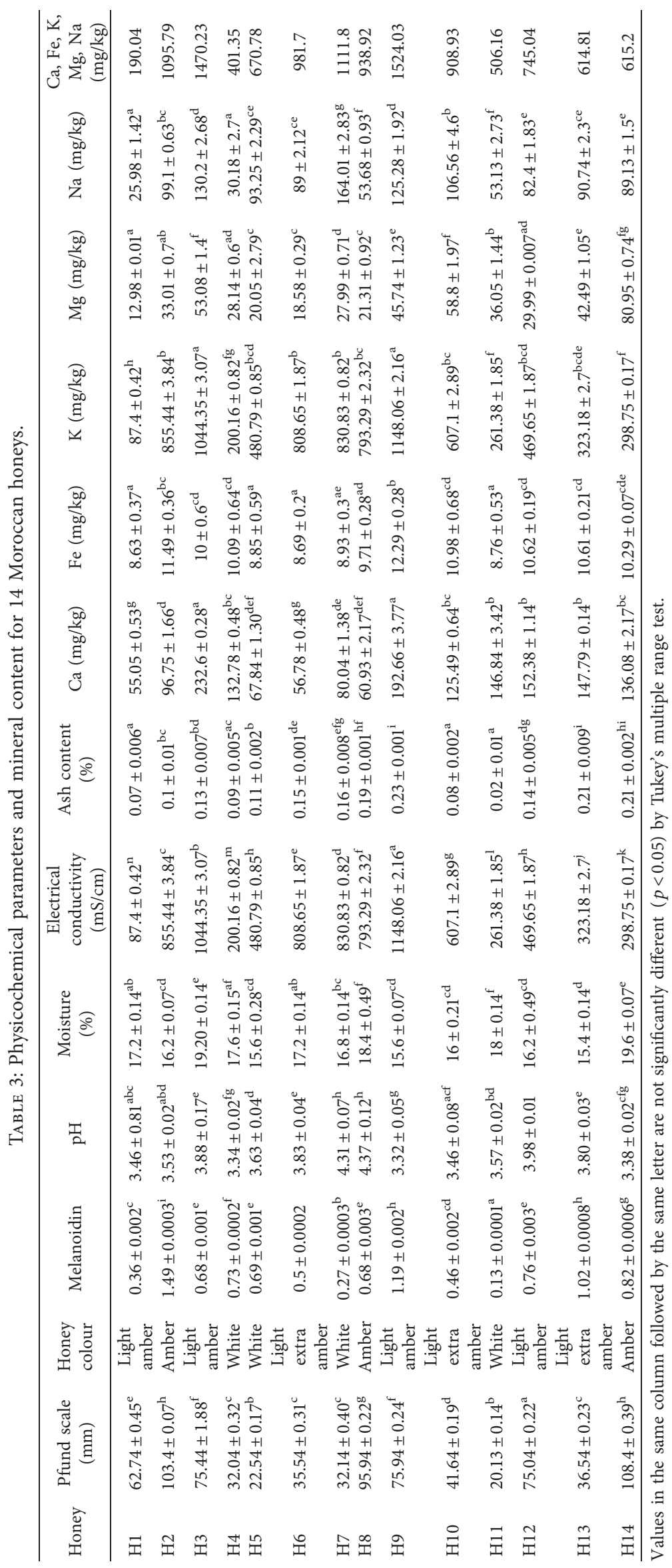




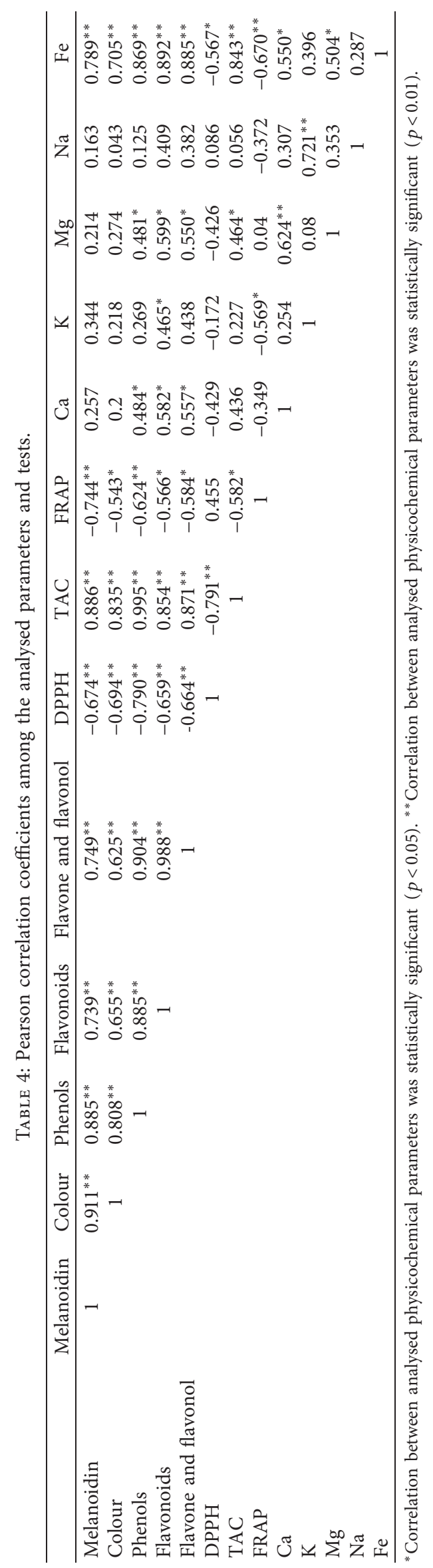


TABLE 5: The content of phenols, flavonoids, flavone, and flavonol, total antioxidant capacity (TAC), and antioxidant activity (DPPH and reducing power) of Moroccan honeys.

\begin{tabular}{|c|c|c|c|c|c|c|}
\hline Honey & $\begin{array}{c}\text { Phenols } \\
\text { (mg GAE/100 g) }\end{array}$ & $\begin{array}{c}\text { Flavonoids } \\
(\mathrm{mg} \mathrm{QE} / 100 \mathrm{~g})\end{array}$ & $\begin{array}{c}\text { Flavone and flavonol } \\
(\mathrm{mg} \mathrm{QE} / 100 \mathrm{~g})\end{array}$ & TAC (mg AAE/100 g) & $\mathrm{DPPH} \mathrm{IC}_{50}(\mathrm{mg} / \mathrm{ml})$ & 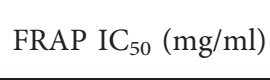 \\
\hline $\mathrm{H} 1$ & $38.06 \pm 7.47^{\mathrm{efg}}$ & $1.11 \pm 3.7^{\mathrm{a}}$ & $0.65 \pm 0.14^{\mathrm{a}}$ & $56.41 \pm 1.91^{\mathrm{efg}}$ & $35.64 \pm 2.26^{\mathrm{g}}$ & $10.51 \pm 0.30^{\mathrm{a}}$ \\
\hline $\mathrm{H} 2$ & $180.18 \pm 0.94^{\mathrm{b}}$ & $21.41 \pm 0.18^{\mathrm{b}}$ & $10.20 \pm 0.63^{b c}$ & $198.53 \pm 1.76^{\mathrm{b}}$ & $5.57 \pm 0.01^{\mathrm{a}}$ & $2.13 \pm 0.10^{\mathrm{b}}$ \\
\hline $\mathrm{H} 3$ & $106.33 \pm 1.89^{\mathrm{d}}$ & $15.96 \pm 1.35^{\mathrm{cd}}$ & $6.75 \pm 2.4^{\mathrm{bcd}}$ & $112.35 \pm 1.33^{\mathrm{cd}}$ & $11.77 \pm 0.02^{\mathrm{d}}$ & $4.14 \pm 0.23^{\mathrm{cd}}$ \\
\hline $\mathrm{H} 4$ & $116.08 \pm 6.87^{\mathrm{d}}$ & $3.62 \pm 0.39^{\mathrm{ae}}$ & $1.9 \pm 3.32^{\mathrm{ad}}$ & $132.96 \pm 8.4^{\mathrm{c}}$ & $16.1 \pm 3.26^{\mathrm{bc}}$ & $3.93 \pm 0.86^{\mathrm{cd}}$ \\
\hline H5 & $58.75 \pm 5.92^{\mathrm{e}}$ & $2.12 \pm 2.3^{\mathrm{ae}}$ & $1.2 \pm 0.35^{\mathrm{ad}}$ & $62.18 \pm 1.19^{\mathrm{ef}}$ & $15.78 \pm 0.16^{\mathrm{bc}}$ & $5.19 \pm 0.09^{\mathrm{g}}$ \\
\hline H6 & $69.9 \pm 3.69^{\mathrm{e}}$ & $9.38 \pm 6.25^{f}$ & $3.55 \pm 5.65^{\mathrm{ab}}$ & $84.38 \pm 0.64^{\mathrm{e}}$ & $14.24 \pm 1.12^{\mathrm{bd}}$ & $5.76 \pm 0.08^{\mathrm{eg}}$ \\
\hline $\mathrm{H} 7$ & $17.35 \pm 2.15^{\mathrm{h}}$ & $0.71 \pm 0.9^{\mathrm{a}}$ & $0.3 \pm 0.84^{\mathrm{a}}$ & $20.57 \pm 0.01^{\mathrm{h}}$ & $48.67 \pm 0.14^{\mathrm{h}}$ & $6.76 \pm 0.32^{\mathrm{f}}$ \\
\hline $\mathrm{H} 8$ & $107.93 \pm 0.21^{\mathrm{d}}$ & $5.16 \pm 4.69^{\mathrm{e}}$ & $2.63 \pm 2.26^{\text {ade }}$ & $126.61 \pm 3.48^{c}$ & $15.34 \pm 0.91^{\text {bce }}$ & $6.12 \pm 0.07^{\mathrm{ef}}$ \\
\hline H9 & $219.026 \pm 2.26^{\mathrm{a}}$ & $36.30 \pm 0.37^{\mathrm{g}}$ & $18.23 \pm 2.82^{\mathrm{g}}$ & $223.86 \pm 2.04^{\mathrm{a}}$ & $4.79 \pm 0.05^{\mathrm{a}}$ & $1.87 \pm 0.18^{\mathrm{b}}$ \\
\hline $\mathrm{H} 10$ & $93.14 \pm 1.42^{\mathrm{d}}$ & $18.21 \pm 1.32^{\mathrm{bc}}$ & $8.23 \pm 5.65^{\text {bce }}$ & $97.72 \pm 2.26^{\mathrm{e}}$ & $18.54 \pm 0.07^{\mathrm{c}}$ & $6.12 \pm 0.08^{\mathrm{ef}}$ \\
\hline $\mathrm{H} 11$ & $44.33 \pm 7.71^{\mathrm{ef}}$ & $1.5 \pm 0.36^{\mathrm{a}}$ & $0.9 \pm 2.26^{\text {adfe }}$ & $52.85 \pm 5.39^{\text {efg }}$ & $16.27 \pm 0.58^{\text {bce }}$ & $10.05 \pm 0.02^{\mathrm{a}}$ \\
\hline $\mathrm{H} 12$ & $103.2 \pm 0.79^{\mathrm{d}}$ & $13.42 \pm 1.17^{\mathrm{df}}$ & $4.83 \pm 0.28^{\mathrm{abf}}$ & $112.1 \pm 1.29^{\mathrm{cd}}$ & $23.1 \pm 0.42^{\text {bcef }}$ & $4.28 \pm 0.34^{\mathrm{c}}$ \\
\hline $\mathrm{H} 13$ & $193.48 \pm 1.58^{b}$ & $22.21 \pm 1.13^{b}$ & $12.23 \pm 2.82^{\mathrm{c}}$ & $202.49 \pm 0.25^{\mathrm{b}}$ & $5.12 \pm 0.09^{\mathrm{a}}$ & $3.16 \pm 0.40^{\mathrm{d}}$ \\
\hline H14 & $158.8 \pm 7.32^{c}$ & $19.79 \pm 0.7^{\mathrm{b}}$ & $8.43 \pm 1.41^{\mathrm{bcf}}$ & $179.24 \pm 0.24^{b c}$ & $7.8 \pm 0.51^{\mathrm{a}}$ & $9.77 \pm 0.08^{\mathrm{a}}$ \\
\hline
\end{tabular}

Values in the same column followed by the same letter are not significantly different $(p<0.05)$ by Tukey's multiple range test.

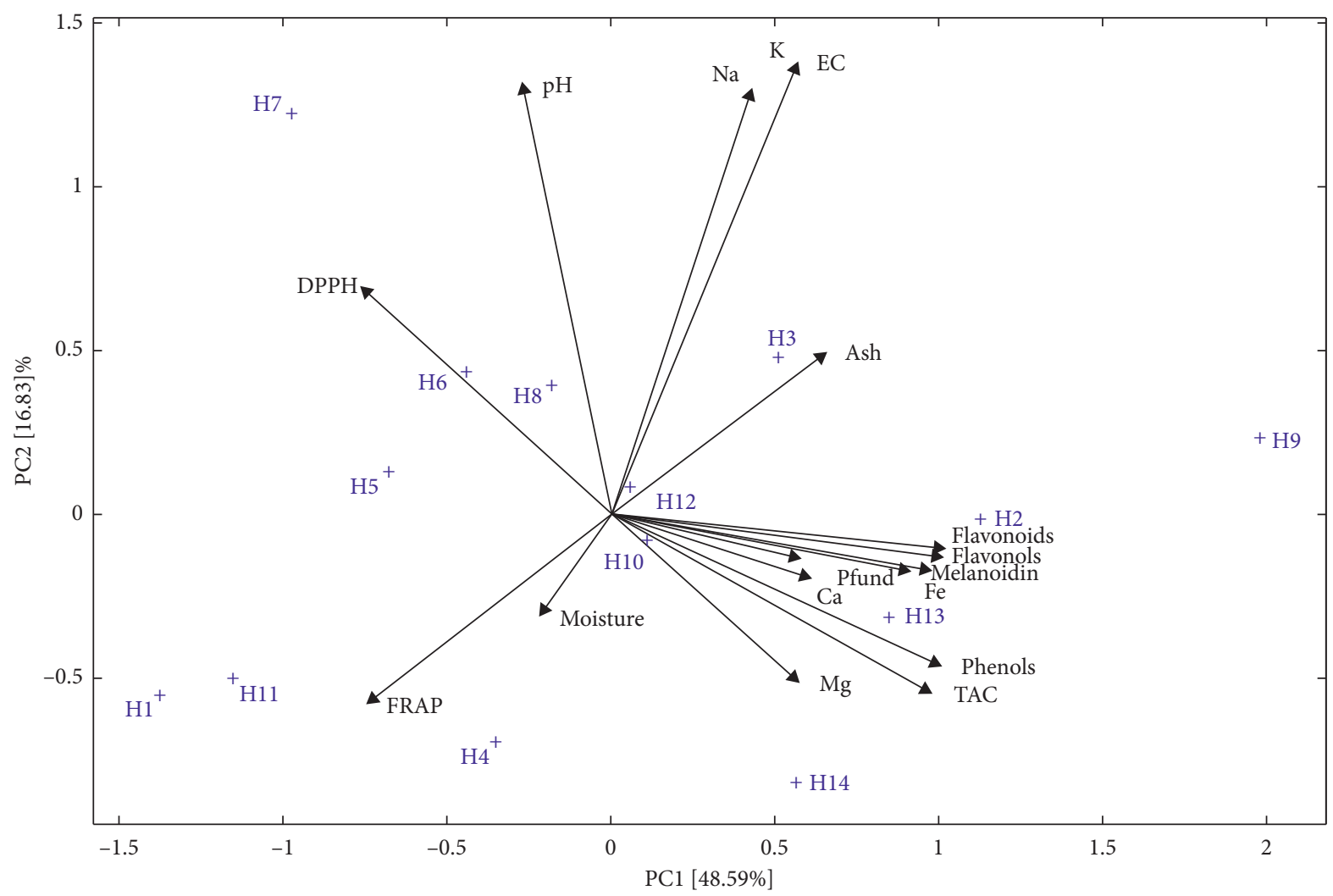

FIGURE 1: Principal component analysis (PCA) using all analysed parameters.

relationship between colour, melanoidins, and antioxidant activity.

3.5. Multivariate Analysis. Figure 1 illustrates the integration of all analysed parameters using principal component analysis (PCA) to illustrate how the samples can be grouped based on their physicochemical characteristics and antioxidant activities. The first two principal components (PCs) explained $65 \%$ of the given raw data. PC1 represented phenols, flavonoids, colour intensity, melanoidins, TAC, Fe, and $\mathrm{Mg}$ in its positive part, while it correlated negatively with the $\mathrm{IC}_{50}$ of DPPH and FRAP antioxidant activities. The PC2 positively represented the ash content, electrical conductivity, $\mathrm{pH}, \mathrm{K}$, and $\mathrm{Na}$ from one side and negatively represented moisture, $\mathrm{Mg}$, and $\mathrm{IC}_{50}$ of FRAP antioxidant activity.

Based on the PC1, explaining the great part of the given data (48.59\%), honey samples with high amount of bioactive 
compounds occupied the right part of the plot. This can be seen by their high contents on polyphenols, flavonoids, flavone, and flavonol. Those samples are $\mathrm{H} 9, \mathrm{H} 2, \mathrm{H} 3$, and H14. Consequently, those samples presented the lowest level of $\mathrm{IC}_{50}$ of both the antioxidant activities DPPH and FRAP. The samples that presented lowest levels of bioactive compounds and high $\mathrm{IC}_{50}$ values of $\mathrm{DPPH}$ and FRAP antioxidant activities were in the left part of the plot.

Regarding the PC2 representing the ash content, electrical conductivity, and the most abundant minerals ( $\mathrm{K}$ and $\mathrm{Na}$ ), the samples can be divided also into two groups. Samples with high mineral content and consequently high ash content and electrical conductivity occupied the top part of the plot and were, namely, H3, H6, H8, and more clearly H7. Samples presenting the lowest levels of the mentioned parameters occupied the opposite part of the plot.

\section{Conclusion}

This work showed that all types of Moroccan honey samples commercialized in Errachidia have high antioxidant potential, as indicated by their high phenolic and flavonoid contents. Moreover, high correlations were observed between different bioactive compounds and antioxidant activities. Even in the absence of a deep chemical characterisation of samples, it was possible to conclude the importance of polyphenols in antioxidant property of honey, given the correlations found between polyphenol contents and different tests used. Considering the microbiological quality, the absence of Salmonella, Shigella, sulfite-reducing Clostridium, coliforms and fecal coliforms, moulds, and yeasts reveals the application of good manufacturing practices by beekeepers.

\section{Data Availability}

The data used to support the fndings of this study are available from the corresponding author upon request.

\section{Conflicts of Interest}

The authors declare that they have no conflicts of interest.

\section{References}

[1] Codex Alimentarius Commission, Codex Alimentarius Commission Standards, Codex Stan 12-1981, 2001.

[2] A. Abselami, A. Tahani, M. Sindic, M. L. Fauconnier, E. Bruneau, and A. Elbachiri, "Physicochemical properties of some honeys produced from different flora of Eastern Morocco," Journal of Materials and Environmental Science, vol. 9, no. 3, pp. 879-886, 2018.

[3] J. Alvarez-Suarez, F. Giampieri, and M. Battino, "Honey as a source of dietary antioxidants: structures, bioavailability and evidence of protective effects against human chronic diseases," Current Medicinal Chemistry, vol. 20, no. 5, pp. 621-638, 2013.

[4] S. Bogdanov, K. Ruoff, and L. Persano Oddo, "Physicochemical methods for the characterisation of unifloral honeys: a review," Apidologie, vol. 35, no. Suppl. 1, pp. S4-S17, 2004.
[5] A. Moujanni, A. K. Essamadi, and A. Terrab, "L'apiculture au Maroc: focus sur la production de miel," International Journal of Innovation and Applied Studies, vol. 20, no. 1, p. 28, 2017.

[6] Y. Elamine, S. Aazza, B. Lyoussi et al., "Preliminary characterization of a Moroccan honey with a predominance of Bupleurum spinosum pollen," Journal of Apicultural Research, vol. 57, no. 1, pp. 153-165, 2018.

[7] N. Malika, F. Mohamed, and E. A. Chakib, "Microbiological and physico-chemical properties of Moroccan honey," International Journal of Agriculture and Biological Sciences, vol. 7, no. 5, pp. 773-776, 2005.

[8] J. A. Snowdon and D. O. Cliverb, "Microorganisms in honey," International Journal of Food Microbiology, vol. 31, no. 1-3, pp. 1-26, 1996.

[9] I. Singh and S. Singh, "Honey moisture reduction and its quality," Journal of Food Science and Technology, vol. 55, no. 10, pp. 3861-3871, 2018.

[10] W. El Khoumsi, A. Hammani, M. Kuper, and A. Bouaziz, "La durabilité du systèmeoasien face à la détérioration des ressources en eaux souterraines: cas de la palmeraie de Tafilalet," Revue Marocaine des Sciences Agronomiques et Vétérinaires, vol. 5, no. 1, 2017.

[11] NP-3788:2002, Microbiologia Alimentar-Regras gerais para a contagem de Microrganismos a $30^{\circ} \mathrm{C}$, Instituto Português da Qualidade, Caparica, Portugal, 2002.

[12] ISO 6579:2002, Microbiology of Food and Animal Feeding Stuffs-Horizontal Method for the Detection of Salmonella Spp, International Standards Organization, Geneva, Switzerland, 2002.

[13] ISO 21567:2004, Microbiologie des Aliments. Méthode Horizontale pour la Recherche de Shigella Spp, International Standards Organization, Geneva, Switzerland, 2004.

[14] ISO 15213:2003, Microbiology of Food and Animal Feeding Stuffs-Horizontal Method for the Enumeration of Sulfite-Reducing Bacteria Growing under Anaerobic Conditions, International Standards Organization, Geneva, Switzerland, 2003.

[15] ISO 4831:2006, Microbiology of Food and Animal Feeding Stuffs-Horizontal Method for the Detection and Enumeration of Coliforms-Most Probable Number Technique, International Standards Organization, Geneva, Switzerland, 2006.

[16] ISO 21527-2:2008, Microbiology of Food and Animal Feeding Stuffs-Horizontal Method for the Enumeration of Yeasts and Moulds-Part 2: Colony Count Technique in Products with Water Activity Less than or Equal to 0.95, International Standards Organization, Geneva, Switzerland, 2008.

[17] O. A. Naab, M. A. Tamame, and M. A. Caccavari, "Palynological and physicochemical characteristics of three unifloral honey types from central Argentina," Spanish Journal of Agricultural Research, vol. 6, no. 4, p. 566, 2008.

[18] K. Brudzynski and D. Miotto, "Honey melanoidins: analysis of the compositions of the high molecular weight melanoidins exhibiting radical-scavenging activity," Food Chemistry, vol. 127, no. 3, pp. 1023-1030, 2011.

[19] L. R. Silva, R. Videira, A. P. Monteiro, P. Valentão, and P. B. Andrade, "Honey from Luso region (Portugal): physicochemical characteristics and mineral contents," Microchemical Journal, vol. 93, no. 1, pp. 73-77, 2009.

[20] V. L. Singleton and J. A. Rossi Jr., "Colorunetry of total phenolics with phosphomolybdic-phosphotungstic acid aeagents," American Journal of Enology and Viticulture, vol. 16, no. 3, pp. 144-158, 1965.

[21] M. I. Khalil, M. Moniruzzaman, L. Boukraâ et al., "Physicochemical and antioxidant properties of Algerian honey," Molecules, vol. 17, no. 9, pp. 11199-11215, 2012. 
[22] E. S. Adithya, M. S. Lakshmi, P. Hephzibah, and J. M. Sasikumar, "In vitro antioxidant, anti-lipid peroxidation activities and HPLC analysis of methanol extracts from bark and stem of Mahonia leschenaultia takeda," Asian Journal of Plant Science and Research, vol. 3, no. 2, pp. 116-126, 2013.

[23] P. Prieto, M. Pineda, and M. Aguilar, "Spectrophotometric quantitation of antioxidant capacity through the formation of a phosphomolybdenum complex: specific application to the determination of vitamin E," Analytical Biochemistry, vol. 269, no. 2, pp. 337-341, 1999.

[24] W. Brand-Williams, M. E. Cuvelier, and C. Berset, "Use of a free radical method to evaluate antioxidant activity," $L W T$ Food Science and Technology, vol. 28, no. 1, pp. 25-30, 1995.

[25] M. Oyaizu, "Studies on products of browning reaction: antioxidative activity of products of Browning reaction prepared from glucosamine," The Japanese Journal of Nutrition and Dietetics, vol. 44, no. 6, pp. 307-315, 1986.

[26] B. O. Omafuvbe and O. O. Akanbi, "Microbiological and physico-chemical properties of some commercial Nigerian honey," African Journal of Microbiology Research, vol. 3, no. 12, 2009.

[27] S. Gomes, L. G. Dias, L. L. Moreira, P. Rodrigues, and L. Estevinho, "Physicochemical, microbiological and antimicrobial properties of commercial honeys from Portugal," Food and Chemical Toxicology, vol. 48, no. 2, pp. 544-548, 2010.

[28] M. Kiš, S. Furmeg, V. J. Tkalec et al., "Characterisation of Croatian honey by physicochemical and microbiological parameters with mold identification," Journal of Food Safety, vol. 38, no. 5, Article ID e12492, 2018.

[29] A. Terrab, M. J. D'iez, and F. J. Heredia, "Characterisation of Moroccan unifloral honeys by their physicochemical characteristics," Food Chemistry, vol. 79, no. 3, pp. 373-379, 2002.

[30] R. El-Haskoury, W. Kriaa, B. Lyoussi, and M. Makni, "Ceratonia siliqua honeys from Morocco: physicochemical properties, mineral contents, and antioxidant activities," Journal of Food and Drug Analysis, vol. 26, no. 1, pp. 67-73, 2018.

[31] S. Aazza, B. Lyoussi, D. Antunes, and M. G. Miguel, "Physicochemical characterization and antioxidant activity of commercial Portuguese honeys," Journal of Food Science, vol. 78, no. 8, pp. C1159-C1165, 2013.

[32] C. Acquarone, P. Buera, and B. Elizalde, "Pattern of $\mathrm{pH}$ and electrical conductivity upon honey dilution as a complementary tool for discriminating geographical origin of honeys," Food Chemistry, vol. 101, no. 2, pp. 695-703, 2007.

[33] S. Serrano, M. Villarejo, R. Espejo, and M. Jodral, "Chemical and physical parameters of Andalusian honey: classification of Citrus and Eucalyptus honeys by discriminant analysis," Food Chemistry, vol. 87, no. 4, pp. 619-625, 2004.

[34] P. Pohl, "Determination of metal content in honey by atomic absorption and emission spectrometries," TrAC Trends in Analytical Chemistry, vol. 28, no. 1, pp. 117-128, 2009.

[35] O. Escuredo, M. C. Seijo, and M. Fernández-González, "Descriptive analysis of Rubus honey from the north-west of Spain: descriptive analysis of Rubus honey," International Journal of Food Science \& Technology, vol. 46, no. 11, pp. 2329-2336, 2011.

[36] F. M. Bueno-Costa, R. C. Zambiazi, B. W. Bohmer et al., "Antibacterial and antioxidant activity of honeys from the state of Rio Grande do Sul, Brazil," LWT-Food Science and Technology, vol. 65, pp. 333-340, 2016. 